\title{
Violência por parceiro íntimo em abuso de álcool perpetrada contra mulheres no climatério
}

Intimate partner violence in cases of alcohol abuse against women in the climacteric

Violencia por compañero íntimo en abuso de alcohol perpetrada contra mujeres en el climaterio

\section{Vilara Maria Mesquita Mendes Pires ${ }^{I}$, Roberta Laíse Gomes Leite Morais ${ }^{I I}$, Letícia Silva dos Santos $^{\mathrm{III}}$, Juliana Costa Machado ${ }^{\mathrm{IV}}$, Caroline Araújo Guedes ${ }^{\mathrm{V}}$, Vanda Palmarella Rodrigues ${ }^{\mathrm{VI}}$}

Resumo: Objetivo: identificar nos registros de ocorrência de uma Delegacia Especializada no Atendimento à Mulher (DEAM), as situações de violência perpetradas por parceiro íntimo em abuso de álcool contra mulheres no climatério. Método: pesquisa qualitativa descritiva, realizada na DEAM de um município do interior baiano. Para a coleta de dados, utilizou-se o sistema de notificação de ocorrências da DEAM e na análise dos dados foi empregada a análise de conteúdo. Resultados: a violência praticada por parceiro íntimo torna-se frequente com o uso abusivo de álcool, sob a forma de violência física, psicológica e sexual e na fase do climatério as agressões foram constantes. Considerações finais: ressalta-se a importância da discussão sobre violência contra as mulheres entre profissionais que atuam na atenção primária à saúde para identificar a violência, realizar atendimento integral e implementar estratégias de prevenção e redução da violência, visando à articulação com os serviços da rede de atenção.

Descritores: Violência contra a mulher; Climatério; Violência por parceiro íntimo; Abuso de Álcool

\footnotetext{
${ }^{\text {I }}$ Enfermeira. Doutora em Família na Sociedade Contemporânea pela Universidade Católica de Salvador. Prof a Adjunto B do Curso de Graduação em Enfermagem da Universidade Estadual do Sudoeste da Bahia (UESB). Jequié. Bahia. Brasil. E-mail: gondim.vilara@gmail.com, https://orcid.org/0000-0003-4964-3050

II Enfermeira. Mestre em Enfermagem e Saúde pela UESB. Prof a Assistente B do Curso de Graduação em Enfermagem da UESB. Jequié. Bahia. Brasil. E-mail: robertalaise@hotmail.com, https://orcid.org/0000-0002-8804-4619

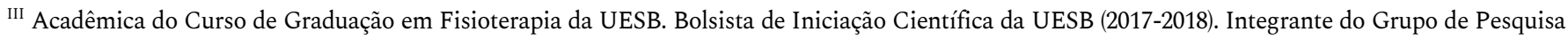
Violência, Saúde e Cultura de Paz. Jequié. Bahia. Brasil. E-mail: leticia_santos.2011@hotmail.com, https://orcid.org/0000-0002-3602-2426

IV Enfermeira. Doutoranda do Programa de Pós-Graduação em Enfermagem e Saúde da UESB. Mestre em Enfermagem e Saúde pela UESB. Prof ${ }^{a}$ Assistente B do Curso de Graduação em Enfermagem da UESB. Jequié. Bahia. Brasil. E-mail: julicmachado@hotmail.com, https://orcid.org/0000-0002-2258-0718

${ }^{v}$ Acadêmica do Curso de Graduação em Fisioterapia da UESB. Discente de Iniciação Científica Voluntária da UESB (2017-2018). Integrante do Grupo de Pesquisa Violência, Saúde e Cultura de Paz. Jequié. Bahia. Brasil. E-mail: caroline.aguedes@gmail.com, https://orcid.org/0000-0002-6305-0086

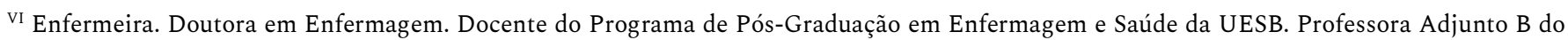
Curso de Graduação em Enfermagem e do Programa de Pós-Graduação em Enfermagem e Saúde da UESB. Jequié. Bahia. Brasil. E-mail: vprodrigues@uesb.edu.br, https://orcid.org/0000-0002-5689-5910
} 
Violência por parceiro íntimo em abuso de álcool perpetrada contra mulheres no climatério | 2

\begin{abstract}
Objective: To identify, in the records of a Women's Police Station (Delegacia Especializada no Atendimento à Mulher, DEAM), violence perpetrated by intoxicated intimate partners against women in the climacteric period. Method: A descriptive qualitative research carried out in the DEAM of a municipality in the inland of Bahia. For data collection and analysis, the DEAM's notification system was used and its content was analyzed. Results: Intimate partner violence and alcohol abuse are frequently related; it happens in the form of physical, psychological and sexual violence. During the climacteric period the aggressions were constant. Final considerations: The importance to discuss violence against women among professionals working in primary health care is highlighted to identify violence, provide integral care and implement strategies to prevent and reduce
\end{abstract} violence, in order to articulate with the services of primary health care.

Descriptors: Violence against women; Climacteric period; Intimate partner violence; Alcohol Abuse

Resumen: Objetivo: identificar, en los registros de ocurrencia, de una Delegacia Especializada no Atendimento à Mulher (DEAM), las situaciones de violencia perpetradas por compañeros íntimos en abuso de alcohol contra mujeres en el climaterio. Método: investigación cualitativa, descriptiva, realizada en la DEAM, de un municipio del interior bahiano. Para la recolección de los datos se utilizó el sistema de notificación de ocurrencias de la DEAM y el análisis de los datos se basó en el análisis de contenido. Resultados: la violencia practicada por los compañeros íntimos ocurre frecuentemente con el uso abusivo del alcohol, por la forma de violencia física, psicológica y sexual, en la fase del climaterio las agresiones son constantes. Consideraciones finales: se resalta la importancia de la discusión sobre la violencia contra las mujeres entre profesionales, que actúan en la atención primaria a la salud, para identificar la violencia, realizar atendimiento integral e implementar estrategias de prevención y reducción de la violencia, para la articulación de los servicios de la red de atención.

Descriptores: Violencia contra la mujer; Climaterio; Violencia por compañero íntimo; Abuso de alcohol

\title{
Introdução
}

De acordo com o Mapa da Violência 2015, Homicídio de Mulheres no Brasil, em 2013 a taxa de feminicídio foi de 4,8 por 100 mil mulheres, com um aumento de $111,1 \%$ em relação a 1980. O Brasil passou a ocupar a 5ª posição nos índices de feminicídio em relação a 83 países, com taxas superiores a muitos países civilizados. ${ }^{1}$

A violência contra as mulheres está presente em diferentes culturas, estando relacionada à questão de gênero, ou seja, do poder estabelecido pelo homem nas relações afetivas. Desde cedo as mulheres são ensinadas a obedecer e satisfazer seus parceiros íntimos, e este comportamento, passou a determinar os papéis de gênero e contribuir para a prática da violência nas relações íntimas..$^{2-4}$ 
Além da relação de controle e dominação do homem sobre a mulher, fatores como o ciúme, a questão financeira, a infidelidade do parceiro, a paternidade sem planejamento e o abuso de álcool, contribuem e intensificam os conflitos nas relações íntimas. ${ }^{5}$

Outro fator importante que passa despercebido, especialmente pelo desconhecimento, é a fase do climatério que compreende a transição entre o período reprodutivo e o não reprodutivo da mulher, envolvendo seu último ciclo menstrual. Essa fase ocorre entre os 35 e aos 65 anos de idade, podendo acarretar mudanças na vida conjugal, profissional e sociocultural da mulher. ${ }^{6}$

Estima-se que 32\% das mulheres no Brasil estejam na faixa etária entre 35 e 65 anos. Destaca-se que as mudanças que ocorrem nesse período como as transformações hormonais, estéticas e psicológicas, podem influenciar na sexualidade feminina e nas relações sexuais. Nessa fase ocorre a diminuição da produção de estrogênio pelos ovários, causando alterações à resposta sexual e desconforto nas relações sexuais, assim como o desinteresse pela prática sexual devido à diminuição da libido. ${ }^{7}$

Essa situação não é aceita nem compreendida pela maioria dos parceiros que desconhecem o fato ou que, simplesmente, impõem o seu desejo acima do desejo da parceira, vinculado à cultura de que o papel feminino é o de reprodutora e se restringe a satisfazer sexualmente o seu parceiro, reprimindo o seu desejo sexual. ${ }^{7}$

Nesse contexto, emerge a Violência por Parceiro Íntimo (VPI) compreendida como qualquer tipo de violência praticada no ambiente doméstico ou em qualquer relação íntima de afeto, independente da visão de agressor vítima, homem/mulher e de coabitação ${ }^{8}$. Portanto, pode ocorrer em qualquer relação entre cônjuges, namorados, ex-cônjuges ou parceiros sem união formalizada, independente do sexo. ${ }^{5}$

O mapa da violência aponta que os atendimentos femininos de situações de violência até os 59 anos de idade, superam os atendimentos masculinos. Ao analisar o conjunto de todas as faixas etárias, observa-se que a violência doméstica é predominante sendo que, no que diz 
Violência por parceiro íntimo em abuso de álcool perpetrada contra mulheres no climatério | 4

respeito ao principal agressor, são parentes imediatos, parceiros e ex-parceiros os principais responsáveis por $67,2 \%$ do total de atendimentos. ${ }^{1}$

A VPI pode se manifestar por meio de violência física apresentando lesões físicas; violência psicológica em forma de ameaças, humilhações, indiferença, isolamento, desprezos e intimidações; violência patrimonial que caracteriza roubo, ou danos aos bens materiais; violência moral, por calúnias, difamações e injúrias; e violência sexual definida como práticas sexuais não consentidas. ${ }^{2-3}$

A violência é ainda desenvolvida dentro de um ciclo vicioso que pode se repetir com mais frequência e intensidade. Inicia-se com alguns conflitos e discussões entre o casal, seguida pelo descontrole físico e emocional do agressor que pratica o ato de violência, até a fase de reconciliação, na qual o agressor se diz arrependido e tenta compensar a companheira. ${ }^{9}$ Estas situações de violência e discussões podem ser potencializadas devido a fase do climatério, marcada pela diminuição do desejo sexual da parceira, assim como pelo consumo abusivo de álcool por parte do parceiro nas relações..$^{5,7,10}$

O abuso de álcool é considerado um problema de saúde pública assim como a violência contra as mulheres e, devido as suas consequências de ordem física, psíquica, social e familiar, se encontram associados e repercutem na vulnerabilidade familiar. O álcool caracteriza-se por ser uma substância altamente consumida no Brasil, tendo o público masculino como principal usuário, podendo ocasionar mudanças de humor e desencadear brigas e discussões por potencializar agressividade, ciúmes e dominação. $5,9-10$

A violência por parceiro íntimo e o abuso de álcool podem ocorrer associados ao longo da vida e influenciar significativamente na construção social de uma pessoa, por exemplo, indivíduos que crescem presenciando atos de violência ou que foram agredidos quando criança, tendem a ser pessoas agressivas no futuro e, possivelmente, abusar do uso do álcool.5,9,11 
Pesquisas estabelecem uma associação positiva consistente entre problemas masculinos e femininos relativos ao abuso de álcool e/ou dependência alcoólica e VPI. Existem evidências científicas de que exista associação entre o álcool e a VPI considerando que grande parte dos indivíduos está sob o efeito de álcool quando praticam a violência, e a probabilidade de ocorrer algum tipo de violência é maior quando os parceiros bebem. . $^{5,911-12}$

Portanto, com relação ao climatério, a maneira com que cada parceiro vivenciará esse período dependerá muito da sua formação cultural. Esse período é permeado por dificuldades que vêm a refletir na vida sexual do casal. Portanto, a má qualidade de vida também é um fator importante que pode prejudicar a realização sexual da mulher. ${ }^{7}$ Sendo assim, compreender os elementos que precipitam a violência no contexto da dependência do álcool e da fase de climatério, é tão importante quanto compreender as relações, comportamentos e contextos que permeiam essas situações e contribuem para tais problemas. ${ }^{5}$

Este estudo traz contribuições ao suscitar a necessidade de ressignificação das práticas de cuidado às mulheres na fase de climatério, por meio da captação das queixas que podem estar associadas à vivência de violência perpetrada pelo parceiro íntimo decorrente do abuso de álcool, de modo a desenvolver o cuidado integral, seja pela prevenção, identificação e intervenções necessárias.

Diante desse contexto, o estudo traz uma questão a ser discutida a partir dos achados nas ocorrências da Delegacia Especializada de Atendimento às Mulheres (DEAM): quais as situações de violência são vivenciadas por mulheres na fase do climatério perpetradas por parceiro íntimo em abuso de álcool?

Este estudo tem o objetivo de identificar nos registros de ocorrência de uma Delegacia Especializada no Atendimento à Mulher as situações de violência perpetradas por parceiro íntimo em abuso de álcool contra mulheres no climatério. O estudo busca contribuir para o 
Violência por parceiro íntimo em abuso de álcool perpetrada contra mulheres no climatério I 6

delineamento de estratégias para a prevenção e redução da violência nas relações entre parceiros íntimos.

\section{Método}

Pesquisa qualitativa descritiva, realizada na DEAM de um município do interior da Bahia (BA). Utilizou-se como critério de inclusão, as ocorrências registradas por mulheres na fase de climatério com idade entre 35 e 65 anos, período que permeia a fase do climatério, período reprodutivo e não reprodutivo da mulher envolvendo seu último ciclo menstrual ${ }^{6}$ que sofreram algum tipo de violência por parceiro íntimo em abuso de álcool, o que totalizou 10 ocorrências.

Trata-se de um recorte do Projeto de Pesquisa "Violência contra a mulher em fase climatério: um estudo a partir dos registros de ocorrência na DEAM no município de Jequié/BA” que atende à Resolução nº466/2012 do Conselho Nacional de Saúde. Foram respeitados todos os aspectos éticos e a pesquisa foi submetido ao Comitê de Ética e Pesquisa da Universidade Estadual do Sudoeste da Bahia (CEP/UESB) com certificado de Apresentação para Apreciação Ética (CAAE) 49739415.7.0000.0055 e, aprovado sob o parecer nำ 1.460.137 de 21/03/2016.

A aproximação ao campo ocorreu após o contato com a Delegada responsável pela DEAM, solicitando agendamento para um encontro com a mesma e com os Agentes que formam a equipe da referida instituição, oportunidade em que as pesquisadoras explicaram o objetivo do estudo e receberam a confirmação do consentimento para a coleta dos dados.

Para a coleta dos dados utilizou-se o sistema de notificação de ocorrências da DEAM do período de janeiro de 2013 a janeiro de 2014, pois nesse período o sistema de notificação de ocorrências estava atualizado e as ocorrências desse período estavam assinadas pela delegada da DEAM, sendo esse o critério para escolha do período. As ocorrências selecionadas foram transcritas para um dispositivo de memória Universal Serial Bus (USB) conforme uma matriz de análise de ocorrência e, posteriormente, analisadas de forma criteriosa e cautelosa. 
Para análise dos dados, utilizou-se a técnica de análise de conteúdo modalidade temática proposta por Bardin, que é entendida como uma apreciação das comunicações visando obter dos conteúdos das mensagens, indicadores (quantitativos ou não) que permitam inferência de conhecimentos relativos às condições de recepção destas mensagens. ${ }^{13}$

Este processo contemplou três etapas: a primeira etapa se consistiu na pré-análise com a realização da leitura flutuante, escolha de documentos, constituição do corpus formado por 10 ocorrências, formulação da questão norteadora e objetivo, índices e indicadores, preparação do material. Na segunda etapa, realizou-se a exploração do material por meio da administração das regras sobre o corpus. Assim, foram aplicadas as regras de recorte, regras de contagem, classificação, agregação por campo semântico e categorização. Na terceira etapa, foi realizado o tratamento dos resultados e interpretações com a aplicação de operações estatísticas, síntese e seleção dos resultados, inferências e interpretação. ${ }^{13}$

A partir dos resultados foram obtidas duas categorias: "Vivência de violência pelas mulheres na fase do climatério perpetradas por seus parceiros íntimos em abuso de álcool” e "Sentimentos presentes nas relações de violência por parceiro íntimo envolvendo o abuso de álcool”.

As ocorrências da pesquisa foram identificadas no texto pela letra $O$ (ocorrências), seguido por um número de acordo a ordem crescente das análises realizadas, ou seja, ocorrência nํ 1 leia-se (O1) e assim sucessivamente.

\section{Resultados e discussão}

As denunciantes vivem com o parceiro agressor há pelo menos 10 anos, algumas relatam que os parceiros passaram a fazer o uso excessivo de álcool e agredi-las posteriormente, outras mulheres relatam sempre ter convivido com o parceiro nessa situação, contudo, todos os 
Violência por parceiro íntimo em abuso de álcool perpetrada contra mulheres no climatério 18

parceiros/ex-parceiros fazem uso de álcool, e, pode-se notar que durante a fase do climatério as agressões se tornaram constantes.

\section{Vivência de violência pelas mulheres na fase do climatério perpetradas por seus parceiros íntimos em abuso de álcool}

Nesta categoria foi possível destacar que, na maioria das ocorrências, as mulheres percebem o aumento do comportamento agressivo, observando, de fato, que o álcool tende a potencializar as relações violentas já existentes no convívio.

Alega a comunicante que seu companheiro [...], vem tecendo constantes ameaças de morte, principalmente quando faz uso de bebida alcoólica, tornando-se uma pessoa violenta. $(\mathrm{O} 1)$

[...] Comunicante informa que seu companheiro faz uso de bebida alcoólica frequentemente e, após o uso do álcool, tece ameaças e difamações. (O2)

[...] Comunicante alega que convive há treze anos com o companheiro e que quando faz uso de bebida alcoólica, fica agressivo, xinga, mantém relações sexuais a força. $(\mathrm{O} 3)$

As mulheres afirmam que após os companheiros fazerem uso de bebida alcoólica, tornam-se violentos e as agridem. A maioria dos casos é de agressão verbal e psicológica, podendo evoluir para a prática de violência física e sexual.

A forma mais comum de violência a ser identificada para a maioria das mulheres, é a violência física, caracterizada por danos visíveis como hematomas, ferimentos e cortes, manifestada por socos, tapas, arremesso de objetos, tentativa de enforcamento, puxões pelos cabelos, chutes, entre outros. ${ }^{3}$ Uma parte das mulheres entende como violência apenas a agressão física, por isso, somente quando há a perda da integridade física, as mulheres recorrem às unidades hospitalares, a DEAM e formalizam o registro da ocorrência. ${ }^{4}$

A violência psicológica consiste em agressões verbais, rejeição e indiferença, humilhações, ameaças, privação de liberdade, ofensas, ente outras. Muitas vezes, é de difícil 
identificação pela mulher, podendo durar por muito tempo, causar danos mentais, pensamentos suicidas, depressão e progredir para a violência física. ${ }^{14}$

A violência por parceiro íntimo inclui o abuso emocional e comportamentos controladores pelo parceiro durante ou após o término da relação, o que pode causar transtornos mentais, dificuldade para a criação de vínculos afetivos, além de aumentar o risco para abuso de álcool e outras drogas. Os sinais nem sempre são aparentes, agravando ainda mais a situação quando os profissionais da rede de atenção apresentam dificuldade para lidar com esses casos, configurando uma deficiência dos serviços. ${ }^{15}$

A violência sexual é compreendida como ato ou tentativa de obter a prática sexual, investidas ou comentários indesejáveis usando a coerção. Em geral, o parceiro íntimo obriga a mulher a manter relações sexuais sem seu consentimento, a força ou com ameaças, fazendo com que as mulheres se sintam um objeto sexual, humilhadas e na condição de submissão. Nesse contexto, evidencia-se a superioridade do homem com essa tentativa da relação sexual forçada, e a recusa da relação sexual pode ser entendida pelo parceiro como uma possível traição e um contrapoder, o que pode desencadear novos conflitos, agressões e a própria violência sexual. ${ }^{16-17}$

O climatério é um período no qual as mulheres podem estar mais vulneráveis à disfunção sexual por conta da baixa de estrogênio e dos fatores emocionais. Estudos demonstraram que a prevalência de disfunção sexual nas mulheres entre 40 e 65 anos é de $67 \%$, tendo $60 \%$ das mulheres afirmado que a atividade sexual diminuiu após a menopausa.7,18

Sendo assim, pode-se inferir que muitas situações de violência sexual podem ocorrer no contexto do climatério, onde pode haver diminuição do desejo sexual da parceira e a recusa de manter relações sexuais com o parceiro em uso abusivo de álcool, podendo culminar no ato sexual forçado. 
Violência por parceiro íntimo em abuso de álcool perpetrada contra mulheres no climatério | 10

Assim, as agressões podem ter como fator desencadeador o abuso de álcool e ocorrerem, frequentemente, quando o parceiro está sob efeito do mesmo, o que pode ocasionar, muitas vezes, agressões verbais na forma de insultos, resultando, algumas vezes, em violência física. ${ }^{14}$

[...] A comunicante diz que o convívio sempre foi difícil devido ao exmarido fazer uso de bebida alcoólica e que já pediu que a mesma reatasse o relacionamento, mas diante da negativa desta, ele tece ameaças de morte dizendo que se ela não for dele, não será de mais ninguém; que não é a primeira vez que o casal rompe a relação. (O5)

A decisão de romper a relação com o parceiro íntimo em virtude do desgaste físico e emocional da mulher é evidenciada na Ocorrência $n^{0} 5$, em que o parceiro não aceita a separação, faz ameaças, exigências, e denota sentimento de posse da mulher. De acordo com os achados de outro estudo quando as mulheres se encorajam para denunciar o parceiro, correm mais risco de serem ameaçadas de morte ou de serem agredidas. ${ }^{19}$

A relação entre casais que se separam mas o parceiro não aceita a separação e passa a perseguir e ameaçar à parceira, ou até obrigá-la a reatar a relação inúmeras vezes, pode ser muito comum devido à relação de controle e dominação por parte do homem sendo também, em grande parte dos casos, um dos motivos das agressões, como na Ocorrência n⿳ำ 5. Considera-se que muitos homens podem apresentar sentimento de posse sobre a mulher e acreditar que a mesma lhe deve obediência..$^{9,14}$

Assim como a ocorrência acima reporta que a convivência entre o casal sempre foi difícil e que a violência sempre ocorreu após o abuso de álcool pelo ex-marido, estudo revela que casais iniciam a relação cientes de que um dos parceiros fazia uso frequente de álcool e afirmaram que as dificuldades no relacionamento estiveram presentes desde o início da união. ${ }^{5}$

Pode-se compreender que, o que acontece na maioria dos casos, é o sentimento de esperança da companheira de que um dia o parceiro vai mudar ou a tentativa constante de mudá-lo, quando na verdade, muitas vezes essa relação pode ser perigosa e sem perspectiva, podendo viver anos no relacionamento conflituoso e agressivo, levando ao desgaste. No entanto, 
muitas mulheres passam a depender, ou acreditam que dependem do marido para a criação dos filhos e para se manter. E assim, os parceiros se aproveitam dessa condição e impõem às suas vontades às companheiras, sendo cada vez mais difícil romper o ciclo da violência.5,14

De acordo com o mencionado pelas mulheres em situação de violência, fatores individuais, tais como o abuso de álcool, têm sido referidos como capazes de precipitar a violência.

[...] A comunicante informa que pediu o dinheiro da feira e o mesmo alegou que não tinha e quando ela falou que ele não tinha dinheiro para feira, estava bebendo, ele teria pego uma tesoura e desferiu golpes na mão esquerda da comunicante. (O6)

Alega a comunicante que o companheiro havia chegado embriagado em casa e teria tomado uma cerveja na conta da comunicante e por isso começaram uma discussão, momento em que o companheiro lhe desferiu uma mordida na testa da comunicante. (O7)

As ocorrências supracitadas demonstram situações em que os companheiros embriagados se deparam com reclamações de suas esposas sobre dívidas e gastos com a bebida. Tais ocorrências reafirmam o que os estudos apontam sobre a significante associação entre o consumo de álcool e a prática de violência por parceiro íntimo pois, quando ingere bebidas alcoólicas, o primeiro comportamento perceptível é a desinibição emocional e euforia, comunicação excessiva e autoconfiança. Essas alterações podem dificultar a tomada de decisões de forma coerente e o controle das ações, potencializando assim a manifestação de violência. ${ }^{20}$

A cultura de que o homem é o provedor do lar e deve monitorar os gastos da casa e, que a mulher deve ser submissa e não questionar justifica a violência, a qual é naturalizada por ambos no meio familiar visto que, culturalmente, esse é o modelo familiar. Além disso, o comportamento alterado devido à substância alcoólica juntamente com esse pensamento, podem provocar atos violentos. ${ }^{2,9}$ 
Violência por parceiro íntimo em abuso de álcool perpetrada contra mulheres no climatério | 12

O abuso de álcool pode estar associado ao comportamento agressivo nas relações, sendo o principal motivo das discussões relatadas. Estão entre outros motivos, gastos com bebida, problemas financeiros e desemprego, a quantidade de tempo que o parceiro permanece no bar e fora de casa, esquecimento, acreditar que sempre está com a razão, xingamentos e ciúmes. No entanto, a maioria desses outros fatores são potencializados pelo uso contínuo ou abusivo de álcool que aumenta, devido a episódios interpessoais estressantes/negativos.,5,21

Alega a comunicante que nos finais de semana o companheiro faz uso de bebida alcoólica e vai até sua residência e a difama usando palavras de baixo calão, diz que os homens da rua todos são seus amantes. [...] the xingou, quer que a vítima saia de casa com os seus dez filhos e que muitas vezes teve que dormir na casa da vizinha, e que o comunicado não contribui em nada com alimentação dos filhos. (O8)

[...] Segundo a comunicante, estava trabalhando e ao retornar para sua residência encontrou seu companheiro visivelmente embriagado e este começou a agredir a vítima verbalmente, ameaçando de agredir fisicamente, segundo a mesma a briga começou por motivo fútil e teve que sair de casa para não ser agredida [...]. (O9)

Nas ocorrências acima é possível notar que a reação das mulheres diante das agressões é de medo e fuga. As parceiras se veem obrigadas a saírem de casa e passar a noite fora por medo do que o parceiro seria capaz de fazer ou para evitar tal situação. Contudo, ainda há casos como na ocorrência nº 8 em que o parceiro quer que a mulher saia de casa.

Muitas vezes permanecem em relações conjugais abusivas por medo do parceiro, medo de vinganças, dificuldades financeiras, dependência econômica e emocional. Diante disso, nas entrelinhas das ocorrências no 8 e no 9 é possível inferir de forma subjetiva, que essas mulheres podem se sujeitar a essa situação para manter a relação, seja por amor ao parceiro, medo, dependência ou submissão e até evitar transtornos para os filhos, muitas vezes, com a crença de que no outro dia a relação com o parceiro retornará ao normal. ${ }^{11}$ 
Estudo evidencia que a maioria dos agressores detidos tinha ingerido álcool, associado a drogas ou isoladamente. Outro estudo afirma que o consumo de álcool tende a desinibir o comportamento das pessoas, muitas vezes, implicando em conflitos nas relações e oferecendo risco de violência. ${ }^{22,14}$

Portanto, embora fatores como o ciúme, problemas financeiros e o abuso de álcool, tenham ocorrido associados em alguns casos, de acordo com as comunicantes, as agressões ocorreram quando os parceiros estavam alcoolizados e sem nenhum outro motivo aparente além do álcool, reafirmando a dominação masculina nesse contexto.

\section{Sentimentos presentes nas relações de violência por parceiro íntimo envolvendo o abuso de álcool}

Os padrões de casamentos ideais, a busca pelo parceiro e pela maternidade, historicamente construídos pela cultura, podem conduzir ao sofrimento e à solidão da mulher na relação. Sob o pensamento que devem ser submissas e agradar o companheiro em quaisquer circunstâncias, tornam-se passivas. Nesse contexto, a manutenção das mulheres nas relações abusivas pode estar relacionada à recusa de viverem sós e o afeto que sentem pelo parceiro. Nessa perspectiva, são direcionadas ao isolamento social, perdem sua individualidade e passam a viver em função do outro. Contudo, muitas mulheres se veem na obrigação de permanecer com parceiros problemáticos e/ou abusivos na tentativa e dever de tentar mudá-los., ${ }^{43}$

Compareceu a esta delegacia a comunicante relatando que conviveu por cerca 20 anos com o companheiro. Porém, não está mais suportando a convivência, pois o mesmo é alcoólatra, não trabalha e vive lhe agredindo física e psicologicamente, lhe xinga com palavras de baixo calão e ainda Ihe ameaça de morte. (O10)

A comunicante convive há cerca de 48 anos com o companheiro e este, ultimamente, começou a fazer uso constante de bebida alcoólica e chega em casa ameaçando e agredindo fisicamente a vítima. Que não aguenta mais essa situação e por isso compareceu nesta unidade policial. (O11) 
Violência por parceiro íntimo em abuso de álcool perpetrada contra mulheres no climatério | 14

Os relatos das mulheres das ocorrências 10 e 11 refletem a falência da relação. Após anos de sofrimento, agressões e passando por uma fase delicada em que estão acontecendo mudanças hormonais e comportamentais em suas vidas, revelam um sentimento de renúncia à sua relação e ao seu parceiro. É possível compreender que a não aceitação e/ou não compreensão das transformações decorrentes do climatério, além do uso constante e progressivo do álcool pelo parceiro, favoreceram o desgaste emocional dessas mulheres, incentivando-as a procurar ajuda.

Com relação às mudanças hormonais e sentimentos, a tristeza e o sofrimento silencioso, assim como a irritabilidade são frequentes em mulheres no climatério, necessitando de atenção. Os sintomas, principalmente a depressão, estariam associados ao sentimento de carência afetiva e culpa, dificuldade nos relacionamentos interpessoais, inutilidade e medo do envelhecimento. ${ }^{24}$

Esses sintomas ocasionados pelo climatério podem ser intensificados frente ao comportamento indiferente do companheiro. Muitas vezes, este passa a desconfiar da mulher, tratá-la com grosseria e impaciência quando esta se recusa a satisfazer os seus desejos, o que pode estar associado ao uso constante de álcool e infidelidade, passando a se distanciar e evitar a parceira ou tornar-se violento e forçar a relação.

Pode-se observar essa relação entre os sintomas em outro estudo, no qual há uma taxa moderada de agressão sexual por parceiro íntimo que tende a ocorrer em conjunto com a violência física, podendo acarretar em consequências psicológicas para a mulher, como o comportamento suicida. No entanto, as mulheres agredidas sexualmente foram mais propensas a praticar ameaças posteriormente ou tentativas de suicídio. ${ }^{25}$ Além disso, podem ocorrer outras consequências, como o aumento da probabilidade do uso de bebida alcóolica pelas mulheres agredidas, desencadeado por situações de indiferença pelo parceiro, como a diminuição da proximidade, críticas e ofensas. ${ }^{21}$ 
Dessa forma, pode-se associar também o sentimento de desconhecimento e incompreensão do homem nessa situação associado ao uso do álcool que, geralmente, é referido como uma forma de relaxar e esquecer os problemas, quando na verdade pode ocasionar ainda mais conflitos e gerar agressividade. E assim, todos esses fatores podem implicar de forma negativa no que se refere ao aspecto psicológico da mulher, principalmente na fase de climatério.

\section{Considerações finais}

O estudo mostrou que a violência contra as mulheres na fase de climatério perpetrada pelo parceiro íntimo tem forte influência dos aspectos sociais e culturais e o abuso de substâncias alcoólicas tende a contribuir para intensificar as agressões. Nesse contexto, são evidenciadas relações de poder do homem sobre a mulher, relacionados à não aceitação da separação, ao ciúme, aos problemas financeiros, ao desrespeito à vontade da parceira, entre outros.

A fase do climatério é ainda um dos fatores agravantes para a violência, tendo em vista o desconhecimento da maioria dos parceiros e incompreensão de alguns. A permanência das mulheres na relação abusiva decorre da percepção de que realmente devem suportar, seja por conta do matrimônio, dos filhos, por amor, por dependência financeira, ou por que se sentem na obrigação de ajudar por dever ou afeto ao parceiro.

A percepção de algumas das mulheres que formalizam as ocorrências, é de que seus parceiros são doentes e que vivem, dessa forma, há algum tempo e só quando as coisas se agravam, pedem ajuda. São mulheres que lidam com essas situações constantemente e acreditam que tais situações se devem somente ao momento do uso abusivo de álcool e que, em seguida, tudo se resolverá. Outra parte das mulheres afirma não suportar mais a permanência em um relacionamento abusivo e se sentem encorajadas a deixarem a relação. 
Violência por parceiro íntimo em abuso de álcool perpetrada contra mulheres no climatério | 16

Ressalta-se então, a importância deste estudo para os profissionais de saúde, sobretudo os que atuam na atenção primária à saúde como enfermeiros, psicólogos, fisioterapeutas, entre outros, tendo em vista os problemas físicos, psíquicos, sexuais e até neurológicos que estas mulheres podem desenvolver e a necessidade da promoção de ações preventivas e de cuidado multiprofissional e intersetorial. Destaca-se ainda a necessidade de um trabalho integrado da DEAM com os serviços de saúde e assistência social, especialmente no caso de mulheres no climatério.

Como limitação do estudo, evidencia-se a escassez de estudos que abordem o climatério no contexto da violência contra mulheres por parceiro íntimo e mais especificamente, sua relação com uso abusivo de álcool, o que requer a necessidade de realizar outras pesquisas que relacionem a violência por parceiro íntimo, abuso de álcool e a fase do climatério.

\section{Referências}

1. Waiselfisz JJ. Mapa da Violência 2015: homicídio de mulheres no Brasil [Internet]. 1ª ed. Brasília (DF); 2015 [acesso em 2019 fev 27]. Disponível em: https://www.mapadaviolencia.org.br/pdf2015/MapaViolencia_2015_mulheres.pdf

2. Griebler CN, Borges JL. Violência contra a mulher: perfil dos envolvidos em boletins de ocorrência da Lei Maria da Penha. Psico (Porto Alegre) [Internet]. 2013 abr [acesso em 2018 jul 08];44(2):215-25. Disponível em: http://revistaseletronicas.pucrs.br/ojs/index.php/revistapsico/article/view/11463

3. Netto LA, Moura MAV, Silva GF, Penna LHG, Pereira ALF. Mulheres em situação de violência pelo parceiro íntimo: tomada de decisão por apoio institucional especializado. Rev Gaúcha Enferm [Internet]. 2015 [acesso em 2017 dez 19];36(esp):135-42. Disponível em: http://www.scielo.br/pdf/rgenf/v36nspe/01026933-rgenf-36-spe-0135.pdf doi: http://dx.doi.org/10.1590/1983-1447.2015.esp.54361

4. Sousa AR, Gomes NP, Estrela FM, Paixão GPN, Pereira A, Couto TM . Violência conjugal: discursos de mulheres e homens envolvidos em processo criminal. Esc Anna Nery Rev Enferm [Internet]. 2018 jan [acesso em 2018 jul 08];22(1):1-7. Disponível em: http://www.scielo.br/pdf/ean/v22n1/pt_1414-8145-ean2177-9465-EAN-2017-0108.pdf doi: 10.1590/2177-9465-EAN-2017-0108

5. Feijó MR, Noto AR, Silva EA, Locatelli DP, Camargo ML, Gebara CFP. Álcool e violência nas relações conjugais: um estudo qualitativo com casais. Psicol Estud [Internet]. 2016 out-dez [acesso em 2018 jul 
08];21(4):581-92.

Disponível

em:

http://www.periodicos.uem.br/ojs/index.php/PsicolEstud/article/view/31556

doi:

http://dx.doi.org/10.4025/psicolestud.v21i4.31556

6. Silva GF, Moura MAV, Almeida MVS, Sá SPC, Queiroz ABA. Influências do climatério para o envelhecimento na percepção de mulheres idosas: subsídios para a enfermagem. Rev Eletrônica Enferm [Internet]. 2015 jul-set [acesso em 2018 jul 08];17(3):1-8. Disponível em: https://www.fen.ufg.br/revista/v17/n3/pdf/v17n3a09.pdf doi: http://dx.doi.org/10.5216/ree.v17i3.29072

7. Santos SMP, Gonçalves SL, Azevedo EB, Pinheiro AKD, Barbosa CA, Costa KNF. A vivência da sexualidade por mulheres no climatério. Rev Enferm UFSM [Internet]. 2014 jan-mar [acesso em 2018 jul 09];4(1):113-22. Disponível em: https://periodicos.ufsm.br/reufsm/article/view/8819 doi: http://dx.doi.org/10.5902/217976928819

8. Moreira AM, Ceccarelli PR. Há múltiplas faces na violência por parceiro íntimo. Rev Méd Minas Gerais [Internet]. 2016 [acesso em 2019 fev 27];26(Supl 8):S351-4. Disponível em: http://rmmg.org/artigo/detalhes/2177

9. Paixão GPN, Gomes NP, Diniz NMF, Couto TM, Vianna LAC, Santos SMP. Situações que precipitam conflitos na relação conjugal: o discurso de mulheres. Texto \& Contexto Enferm [Internet]. 2014 out-dez [acesso em 2018 jul 08];23(4):1041-9. Disponível em: http:/www.scielo.br/pdf/tce/v23n4/pt_0104-0707-tce23-04-01041.pdf doi: http://dx.doi.org/10.1590/0104-07072014003290013

10. Vieira LB, Cortes LF, Padoin SMM, Souza IEO, Paula CC, Terra MG. Abuso de álcool e drogas e violência contra as mulheres: denúncias de vividos. Rev Bras Enferm [Internet]. 2014 maio-jun [acesso em 2018 jul 08];67(3):366-72. Disponível em: http://www.scielo.br/pdf/reben/v67n3/0034-7167-reben-67-030366.pdf

11. Zaleski M, Pinsky I, Laranjeira R, Ramisetty-Mikler S, Caetano R. Violência entre parceiros íntimos e consumo de álcool. Rev Saúde Pública [Internet]. 2010 jan [acesso em 2018 jul 08];44(1):53-9. Disponível em: http://www.scielo.br/pdf/rsp/v44n1/06.pdf

12. Lipsky S, Caetano R, Field CA, Larkin GL. Is there a relationship between victim and partner alcohol use during an intimate partner violence event? Findings from an urban emergency department study of abused women. J Stud Alcohol [Internet]. 2005 [acesso em 2019 fev 27];66(3):407-12. Disponível em: https://www.ncbi.nlm.nih.gov/pubmed/16047531 doi: https://doi.org/10.15288/jsa.2005.66.407

13. Bardin, L. Análise de conteúdo. São Paulo: Edições 70; 2011.

14. Zacan N, Wassermann V, Lima GQ. Violência doméstica a partir dos discursos de mulheres agredidas. Pensando Fam [Internet]. 2013 jul [acesso em 2018 jul 08];17(1):63-76. Disponível em: http://pepsic.bvsalud.org/scielo.php?script=sci_arttext\&pid=S1679-494X2013000100007 
Violência por parceiro íntimo em abuso de álcool perpetrada contra mulheres no climatério | 18

15. Garcia LP, Silva GDM. Violência por parceiro íntimo: perfil dos atendimentos em serviços de urgência e emergência nas capitais dos estados brasileiros, 2014. Cad Saúde Pública [Internet]. 2018 [acesso em 2019 jan 11];34(4):e00062317. Disponível em: http://www.scielo.br/scielo.php?script=sci_arttext\&pid=S0102-311X2018000405004\&lng=en. doi: 10.1590/0102-311X00062317

16. Delziovo CR, Coelho EBS, d'Orsi E, Lindner SR. Violência sexual contra a mulher e o atendimento no setor saúde em Santa Catarina - Brasil. Ciênc Saúde Colet [Internet]. 2018 maio [acesso em 2018 set 09];23(5):1687-96. Disponível em: http://www.scielo.br/pdf/csc/v23n5/1413-8123-csc-23-05-1687.pdf doi: 10.1590/1413-81232018235.20112016

17. Acosta DF, Gomes VLO, Fonseca AD, Gomes GC. Violência contra a mulher por parceiro íntimo: (in)visibilidade do problema. Texto \& Contexto Enferm [Internet]. 2015 jan-mar [acesso em 2018 set 09];24(1):121-7. Disponível em: http://www.scielo.br/pdf/tce/v24n1/pt_0104-0707-tce-24-01-00121.pdf doi: 10.1590/0104-07072015001770013

18. Cavalcanti IF, Farias PN, Ithamar L, Silva VM, Lemos A. Função sexual e fatores associados à disfunção sexual em mulheres no climatério. Rev Bras Ginecol Obstet [Internet]. 2014 [acesso em 2018 jul 08];36(11):497-502. Disponível em: http://www.scielo.br/pdf/rbgo/v36n11/0100-7203-rbgo-36-11-0497.pdf doi: 10.1590/SO100-720320140004985

19. Melo AG, Pederiva R. Violência contra a mulher: a permanência da mulher na relação violenta após a denúncia e a retirada da queixa. Unoesc \& Ciênc - ACBS [Internet]. 2016 jul-dez [acesso em 2018 set 09];7(2):221-8. Disponível em: http://editora.unoesc.edu.br/index.php/acbs/article/view/11757/pdf

20. Araújo WSC, Silva AF, Estrela FM, Lírio JGS, Cruz MA, Santos, JR, et al. A influência do consumo de bebidas alcoólicas na ocorrência de violência por parceiro íntimo: revisão integrativa. Arq Ciências Saúde UNIPAR [Internet]. 2018 maio-ago [acesso em 2018 set 09];22(2):117-22. Disponível em: http://www.revistas.unipar.br/index.php/saude/article/view/6380/3572 doi: 10.25110/arqsaude.v22i2.2018.680

21. Derrick JL, Testa M. Temporal effects of perpetrating or receiving intimate partner aggression on alcohol consumption: a daily diary study of community couples. J Stud Alcohol Drugs [Internet]. 2017 mar [acesso em 2018 jul 08];78(2):213-21. Disponível em: https:/www.ncbi.nlm.nih.gov/pmc/articles/PMC5554102/ doi: 10.15288/jsad.2017.78.213

22. Madureira AB, Raimondo ML, Ferraz MIR, Marcovicz GV, Labronici LM, Mantovani MF. Perfil de homens autores de violência contra mulheres detidos em flagrante: contribuições para o enfrentamento. Esc Anna Nery Rev Enferm [Internet]. 2014 out-dez [acesso em 2018 jul 08];18(4):600-6. Disponível em: http://www.scielo.br/pdf/ean/v18n4/1414-8145-ean-18-04-0600.pdf doi: 10.5935/1414-8145.20140085 
23. Peixoto MM, Heilborn ML. Mulheres que amam demais: conjugalidades e narrativas de experiência de sofrimento. Estud Fem [Internet]. 2016 jan-abr [acesso em 2018 jul 08];24(1):45-62. Disponível em: http://www.scielo.br/pdf/ref/v24n1/1805-9584-ref-24-01-00045.pdf doi: http://dx.doi.org/10.1590/18059584-2016v24n1p45

24. Cardoso MR, Camargo MJG. Percepções sobre as mudanças nas atividades cotidianas e nos papéis ocupacionais de mulheres no climatério. Cad Ter Ocup [Internet]. 2015 jul [acesso em 2018 set 09];23(3):553-69. Disponível em: http://www.cadernosdeterapiaocupacional.ufscar.br/index.php/cadernos/article/view/1024/639 doi: http://dx.doi.org/10.4322/0104-4931.ctoAO0574

25. Pengpid S, Peltzer K, Laosee O, Suthisukon K. Intimate partner sexual violence and risk for femicide, suicidality and substance use among women in antenatal care and general out-patients in Thailand. BMC Womens Health [Internet]. 2018 fev [acesso em 2018 jul 08];18(37). Disponível em: https://www.ncbi.nlm.nih.gov/pmc/articles/PMC5802095/ doi: 10.1186/s12905-018-0526-z

\section{Autor correspondente}

Vilara Maria Mesquita Mendes Pires

E-mail: gondim.vilara@gmail.com

Endereço: Av. José Moreira Sobrinho, S/N. Bairro Jequiezinho. Jequié-BA.

CEP: 45.206-510.

\section{Contribuições de Autoria}

\section{1 - Vilara Maria Mesquita Mendes Pires}

A autora participou efetivamente da concepção e planejamento do projeto de pesquisa, obtenção, análise e interpretação dos dados, redação e revisão crítica.

\section{2 - Roberta Laíse Gomes Leite Morais}

A autora participou efetivamente da concepção e planejamento do projeto de pesquisa, obtenção, análise e interpretação dos dados, redação e revisão crítica.

\section{3 - Letícia Silva dos Santos}

A autora participou efetivamente da concepção e planejamento do projeto de pesquisa, obtenção, análise e interpretação dos dados, redação e revisão crítica.

\section{4 - Juliana Costa Machado}

A autora participou efetivamente da concepção e planejamento do projeto de pesquisa, obtenção, análise e interpretação dos dados, redação e revisão crítica.

\section{5 - Caroline Araújo Guedes}


Violência por parceiro íntimo em abuso de álcool perpetrada contra mulheres no climatério | 20

A autora participou efetivamente da concepção e planejamento do projeto de pesquisa, obtenção, análise e interpretação dos dados, redação e revisão crítica.

\section{6 - Vanda Palmarella Rodrigues}

A autora participou efetivamente da concepção e planejamento do projeto de pesquisa, obtenção, análise e interpretação dos dados, redação e revisão crítica.

\section{Como citar este artigo}

Pires VMM, Morais RLL, Santos LS, Juliana Costa Machado, Guedes CA, Rodrigues VP. Nexos e reflexos da adaptação do enfermeiro à cultura organizacional. Rev. Enferm. UFSM. 2019 [Acesso em: 2019 jun 15];vol 9 e45:120. DOI:https://doi.org/10.5902/2179769234201 